\title{
Emission Reduction in HSDI Diesel Engine-Multi pulse Injection
}

\author{
K. Bala Showry ${ }^{1}$ \\ ${ }^{\text {I}}$ (Professor, Mechanical Engineering, VNR VJIET, Hyderabad, INDIA)
}

\begin{abstract}
In order to meet the stringent emission standards significant efforts have been imparted to the research and development of cleaner IC engines. Diesel combustion and the formation of pollutants are directly influenced by spatial and temporal distribution of the fuel injected. The development and validation of computational fluid dynamics (CFD) models for diesel engine combustion and emissions is described. The complexity of diesel combustion requires simulations with many complex interacting sub models in order to have a success in improving the performance and to reduce the emissions. In the present work an attempt has been made to develop a multidimensional axe-symmetric model for CI engine combustion and emissions. Later simulations have been carried out using Multi pulse injection for single and three pulses (split injection) for which commercial validation tool FLUENT was used for simulation. The tool solves basic governing equations of fluid flow that is continuity, momentum, species transport and energy equation. Using finite volume method turbulence was modeled by using $R N G K$ - $\varepsilon$ model. Injection was modeled using La Grangian approach and reaction was modeled using non premixed combustion which considers the effects of turbulence and detailed chemical mechanism into account to model the reaction rates. The specific heats were approximated using piecewise polynomials. Subsequently the simulated results have been validated with the existing experimental values.The peak pressure obtained by simulation for single $10 \%$ higher than to that of experimental value. Whereas for triple injections 5\% higher than to that of experimental value. When compared to triple injection. $\mathrm{NO}_{X}$ have been decreased in simulation for single and triple injections by $15 \%$, and $20 \%$.. The simulated value of soot for single, double and triple injections are $12 \%$ and $12 \%$ lesser than the experimental values. For quadruple injection the soot levels were almost negligible. The simulated heat release rates for single and triple were reduced by $12 \%$, and $11 \%$. For quadruple injection heat release is reduced same as to that of triple injection.
\end{abstract}

Keywords: Multi pulse injection, Computational Fluid Dynamics, Start of injection, Duration of injection

\section{Introduction}

Increasing environmental concerns and legislated emission standards have led to the necessity of considering both conventional and unconventional means for reducing soot and $\mathrm{NO}_{\mathrm{X}}$ emissions in diesel engines, which is also a motivation of the present study. For example, diesel engine manufacturers are facing the challenges of the extremely low diesel engine -out soot emission mandates to be implemented in the near future. Engine simulation, compared to expensive engine experiments, is an efficient way to investigate various novel ideas to improve current engine performance, and hence becomes an essential part of engine research and development. In addition, simulations can investigate the transient properties of physical processes capabilities and model parameter uncertainties in many of the diesel spray and combustion related mechanisms limit the possibility of using detailed chemistry description of the soot formation process. On the other hand, the widely applied and highly -efficient empirical soot models have become less sufficient for the emerging demands for accuracy and detailed soot particulate information. For example, newly proposed emission mandates will specifically enforce the emitted soot particulate's size.

\section{Literature Review}

Multiple injections divide the total quantity of the fuel into two or more injections per combustion cycle. Splitting the injection sequence into two events is called pilot or split injection. A pilot injection is usually defined as an injection where $15 \%$ or less of the total mass of fuel is injected which reduces combustion noise and allow the use of poor ignition quality fuel (low cetane numbers) [2]. Many researchers are now investigating pilot and split injection as an effective means to simultaneously reduce $\mathrm{NO}_{\mathrm{X}}$ and particulate emission. Shundhoh.et al. [3] reported that $\mathrm{NO}_{\mathrm{X}}$ could be reduced by 35\%, and smoke by 60 to $80 \%$, without a penalty in fuel economy if pilot injection was used in conjunction with high pressure injection. Yamaki.et al. [4] investigated the effects of pilot injection on exhaust emissions in a turbocharged heavy duty Diesel engine and found that with partial load, when the pilot fuel quantity was increased, Fuel consumption and smoke was increased, but $\mathrm{NO}_{\mathrm{X}}$ was found to decrease and then increase. Minami et al. [5] studied the effects of pilot 
injection $\mathrm{s}$ in a turbocharged DI diesel engine and found that the pilot injection was effective to reduce $\mathrm{NO}_{\mathrm{x}}$ and $\mathrm{HC}$ at low load conditions, through it deteriorated smoke to some degree. Zhang et al. [6] used a single cylinder HSDI diesel engine to investigate the effect of pilot injection with EGR on soot, $\mathrm{NO}_{\mathrm{X}}$ and combustion noise, and found that the pilot injection increased soot emission. Nehmer and Reitz.et al. [7] Studied the effect of split injection in a heavy -duty diesel engine by varying the amount of fuel in first injection from 10 to $75 \%$ of the total amount of fuel. They found that split injection better utilized the air charge and allowed combustion to continue later into the power stroke than for a single injection case, without increased levels of soot production. Tow et al. [8] found that using a double injection with a relatively long dwell on a heavy duty engine resulted in reduction of particulate emissions by a factor of three with no increase in $\mathrm{NO}_{\mathrm{x}}$ and only a slight increase in BSFC compared to a single injection. Han et al. [9] Multidimensional computations carried out to understand the mechanism of soot and $\mathrm{NO}_{\mathrm{X}}$ emissions reduction in a heavy - duty diesel engine with multiple injections. The high momentum injected fuel penetrates to the fuel rich, relatively low temperature region at the jet tip and continuously replenishes the rich region, producing soot .However in a split injection, the second injection enters into a relatively fuel -lean and high temperature region that is left over from the combustion of first injection. Therefore, soot formation is significantly reduced. Tow et al. [8] pointed out that the dwell between injections was very important to control soot production and there would exist an optimal dwell at a particular engine operating condition. Durnholz.et al. [10] investigated the influence of pilot injection for a turbocharged and intercooled DI diesel engine for passenger cars. Their optimized pilot injection contained about $1.5 \mathrm{~mm}^{3}$ of the fuel in the pilot injection independent of engine load and their optimal dwell was $15^{\circ} \mathrm{CA}$. Fuchs and Rutland [1] found that high swirl ratios distributed the fuel such that it remained in the bowl, thus depleting almost all of the bowl oxygen during combustion. Therefore, they asserted that in high swirl ratio split injection cases the dwell should be optimized to prevent the second injection from landing in the fuel rich region left in the bowl from the first injection. D.A.Peirpont.et al. [11] Studied multiple injections are effective at reducing particulate. Two nozzle spray angles were used with included spray angles of $125^{\circ}$ and $140^{\circ}$ the results show that the combined use of EGR and multiple injections is very effective at simultaneously reducing particulate and $\mathrm{NO}_{\mathrm{X}}$. D.T.Montgomery et al.[12] observed the emissions and performance effects of exhaust gas recirculation (EGR) and multiple injections on the emission of oxides of nitrogen $\left(\mathrm{NO}_{\mathrm{X}}\right)$, particulate emissions, and brake specific fuel consumption (BSFC) over a wide range of engine operating conditions. $\mathrm{NO}_{\mathrm{X}}$ and particulate could be simultaneously reduced to 2.2 and 0.07 grams per bhp hour respectively. ManshikKim.et.al. [13] performed numerical simulations to investigate the combustion process in the Premixed Compression Ignition (PCI) regime in a light-duty diesel engine. Simulation results have shown good levels of agreement with the measured in-cylinder pressure, heat release rate and exhaust emissions. Mark P. et al. [14] worked on In-cylinder spray, mixing, combustion, and pollutant formation processes with early fuel injection $\left(\mathrm{SOI}=-22^{\circ}\right.$ ATDC) at two different charge densities were studied. W. L. Hardy et al. [15] performed Optimizations on a single-cylinder heavy-duty. A micro-genetic algorithm was utilized to optimize a hybrid, double-injection strategy. The optimization produced a parameter set that met the 2007 and 2010 PM emissions mandate of $0.0134 \mathrm{~g} / \mathrm{kW} \mathrm{hr}$, and was within the limits.

\section{Computational Fluid Dynamics}

CFD is a sophisticated analysis technique that the analyst to predict transfer of heat, chemical reaction, and fluid flow behavior etc. CFD is based on the fundamental governing equations of fluid dynamics- the continuity, momentum, and energy equation. It is a powerful tool to carry out numerical experiments. This research uses the Computational Fluid Dynamics -FLUENT 6.3 software package. The process of utilizing FLUENT can be assumed in firstly, the geometry and gird is created using GAMBIT. T Grid can be used to generate 2D triangular, 3D tetrahedral or 2D and 3D hybrid volumes mesh from an existing boundary mesh. Another alternative of creating grids for FLUENT is using ANSYS or IDEAS and Geo Mesh are the names of FLUENT Pre-processors that were used before the introduction of GAMBIT. Once a grid has been read into FLUENT, all remaining operations are performed with in the solver. These include setting the boundary conditions, defining fluid properties, and material properties, executing the solution, refining the grid, viewing and post- processing the results.

\section{Governing Equation}

In CFD, fluid flows are stimulated by numerical solving partial differential equations that governs the transport of flow quantities also known as flow variables. These variables include mass, momentum, energy, turbulent quantities, and species concentrations. In designing the POME- nozzle, the basic governing equations that will be used are the conservation of mass, momentum and energy equations. 


\section{Discritization Method}

The method contains settings that control the discritization of the convection terms in the solution equations. It is a numerical method to solve the above equation by discritization to the partial differential Equations on a computational grid, the formation of a set algebraic equations and the solution of the algebraic equations. FLUENT allows choosing the discritization scheme for the convection terms of each governing equation. The numerical method is a discrete solution of the flow field, which is comprised of the values of the flow variables at the grid points. One of the most important terms that need to be discritized is convection. Second- order accuracy is automatically used for the viscous terms. The mathematical code uses a control volume technique to covert the governing equations that can be solved numerically. It consists of integration the governing equations about each control volume.

\section{Upwind Scheme}

Due to the computational domain, the initialized values are quite different from those expected in the final solution after the iteration process has begun. For this reason, first order UPWIND scheme is utilized until a more realistic solution is achieved, after which a more accurate second order UPWIND scheme could be implemented.

\section{Mathematical Modeling And Simulation}

To predict the parameters cycle peak pressures, heat release rate, temperature and the influence of different parameters on the formation of oxides of nitrogen, carbon monoxide, and soot using CFD technique, the following flow governing equations are to be solved

\section{Continuity and Momentum Equation}

For all flows, FLUENT solves conservation equations for mass and momentum. For flows involving heat transfer or compressibility, an additional equation for energy conservation is solved. For flows involving species mixing or reactions, a species conservation equation is solved or if the non premixed combustion model is used, conservation equations for the mixture fraction and its variance are solved. Additional transport equations are also solved when the flow turbulent. The conservation equations relevant to heat transfer, turbulence modeling and species transport will be discussed here.

\section{The Mass Conservation Equation}

$$
\frac{\partial p}{\partial t}+\nabla \cdot(\rho \vec{v})=S_{m}
$$

Equation (1) is the general form of the mass conservation equation and is valid for incompressible flows. The source $S_{m}$ is the mass added to the continuous phase from the dispersed second phase and any user-defined sources.

For 2D Axi -symmetric geometries, the continuity equation is given by

$$
\frac{\partial p}{\partial t}+\frac{\partial}{\partial x}\left(\rho v_{x}\right)+\frac{\partial}{\partial r}\left(\rho v_{r}\right)+\frac{\rho v_{r}}{r}=S_{m}
$$

Where $x$ is the axial coordinate, $r$ is the radial co- ordinate, $v_{x}$ is the axial velocity, and $v_{r \text { is the radial }}$ velocity.

\section{Momentum Conservation Equations}

Conservation of momentum in an inertial (non - accelerating) reference is given by

$$
\frac{\partial}{\partial t}(\rho \vec{v})+\nabla \cdot(\rho \vec{v} \vec{v})=-\nabla p+\varsigma \nabla \cdot(\overline{\bar{T}})+\rho \vec{g}+\vec{F}
$$

Where $p$ is static pressure, $\quad \overline{\bar{T}}$ is the stress tensor (described below), and $\rho \vec{g}$ and $\vec{F}$ are the gravitational body force and external body forces respectively. $\vec{F}$ also contains other model-dependent source terms such as porous media and user defined sources.

The stress tensor $\overline{\bar{T}}$ is given by 
$\overline{\bar{T}}=\mu\left[\left(\nabla \vec{v}+\nabla \vec{v}^{T}\right)-\frac{2}{3} \nabla \cdot \vec{v} I\right]$

where $\mu$ is the molecular viscosity, $I$ is the unit tensor, and second term on the right hand side is the effect of volume dilation.

For 2D axi-symmetric geometries, the axial and radial momentum conservation equations are given by

$\frac{\partial}{\partial t}\left(\rho v_{x}\right)+\frac{1}{r} \frac{\partial}{\partial x}\left(r \rho v_{x} v_{x}\right)+\frac{1}{r} \frac{\partial}{\partial r}\left(r \rho v_{r} v_{x}\right)=-\frac{\partial p}{\partial x}+\frac{1}{r} \frac{\partial}{\partial x}\left[r \mu\left(2 \frac{\partial v_{x}}{\partial x}-\frac{2}{3}(\nabla \cdot \vec{v})\right)\right]+$

$\frac{1}{r} \frac{\partial}{\partial r}\left[r \mu\left(\frac{\partial v_{x}}{\partial r}+\frac{\partial v_{r}}{\partial x}\right)\right]+F_{x}$

And

$\frac{\partial}{\partial t}\left(\rho v_{r}\right)+\frac{1}{r} \frac{\partial}{\partial x}\left(r \rho v_{x} v_{r}\right)+\frac{1}{r}\left(r \rho v_{r} v_{r}\right)=-\frac{\partial p}{\partial r}+\frac{1}{r} \frac{\partial}{\partial x}\left[r \mu\left(\frac{\partial v_{r}}{\partial x}+\frac{\partial v_{x}}{\partial r}\right)\right]+\frac{1}{r} \frac{\partial}{\partial r}\left[r \mu\left(2 \frac{\partial v_{r}}{\partial r}-\frac{2}{3}(\nabla \cdot \vec{v})\right)\right]$

$-2 \mu \frac{v_{r}}{\partial r}+\frac{2}{3} \frac{\mu}{r}(\nabla \cdot \vec{v})+\rho \frac{v_{z}^{2}}{r}+F_{r}$

Where

$\nabla \cdot \vec{v}=\frac{\partial v_{x}}{\partial x}+\frac{\partial v_{r}}{\partial r}+\frac{v_{r}}{r}$

and $v_{z}$ is the swirl velocity.

\section{Computational Mech And Engine Details}

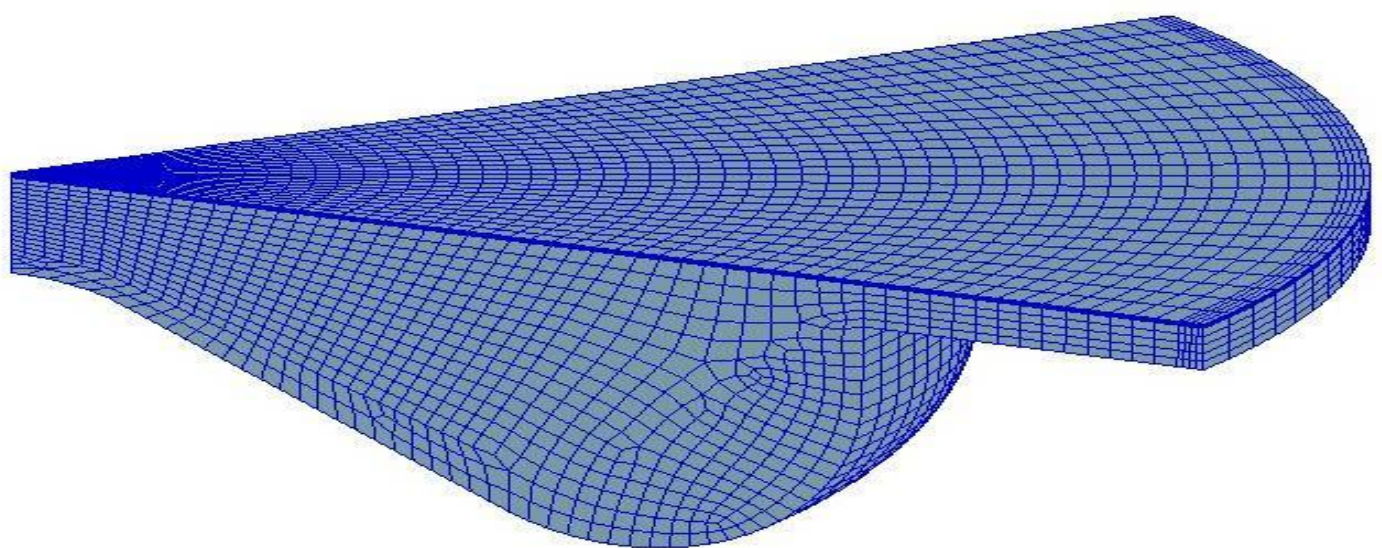

Figure 1 Computational Mesh

Table 1Simulation Engine Details

\begin{tabular}{|l|l|}
\hline Engine Type & $\begin{array}{l}\text { Caterpillar 3406, Single cylinder } \\
\text { Direct injection, 4 valve }\end{array}$ \\
\hline Bore & $137.2 \mathrm{~mm}$ \\
\hline Stroke & $165.2 \mathrm{~mm}$ \\
\hline Compression ratio & $15.1: 1$ \\
\hline Engine speed & $2100 \mathrm{rpm}$ \\
\hline Atomization & Pressure swirl \\
\hline Atomizer dispersion angle & $6^{\circ}$ \\
\hline
\end{tabular}


Table 2 Fuel System Specifications

\begin{tabular}{|l|l|}
\hline Injector type & $\begin{array}{l}\text { Electronically controlled } \\
\text { common rail injector }\end{array}$ \\
\hline Injection pressure & Variable up to $120 \mathrm{M} \mathrm{pa}$ \\
\hline Number of orifices & 6 \\
\hline orifice diameter & $0.26 \mathrm{~mm}$ \\
\hline Spray included angle & $140^{\circ}$ \\
\hline Injection Approach & La-grangian \\
\hline Turbulence model & $\mathrm{RNG} \mathrm{K- \varepsilon}$ \\
\hline Mass flow rate & $0.0356 \mathrm{Kg} / \mathrm{sec}$ \\
\hline Time step & $6.6666^{*}-5$ \\
\hline Start of injection & $20^{\circ} \mathrm{bTDC}$ \\
\hline Duration of injection & $24^{\circ}$ \\
\hline Fuel & Diesel \\
\hline
\end{tabular}

\section{Validation Of Simulation Results}

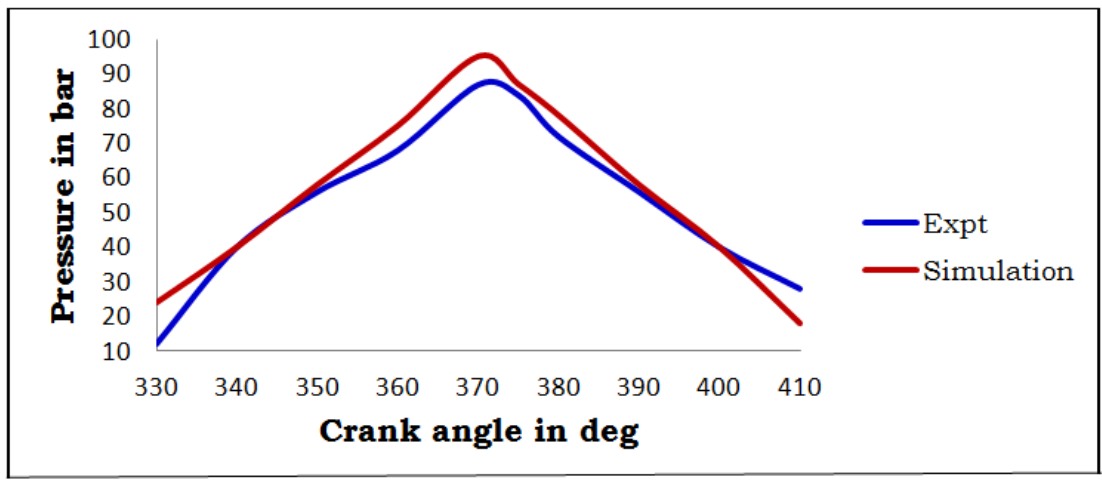

Figure 2 P- $\theta$ Curve for single injection

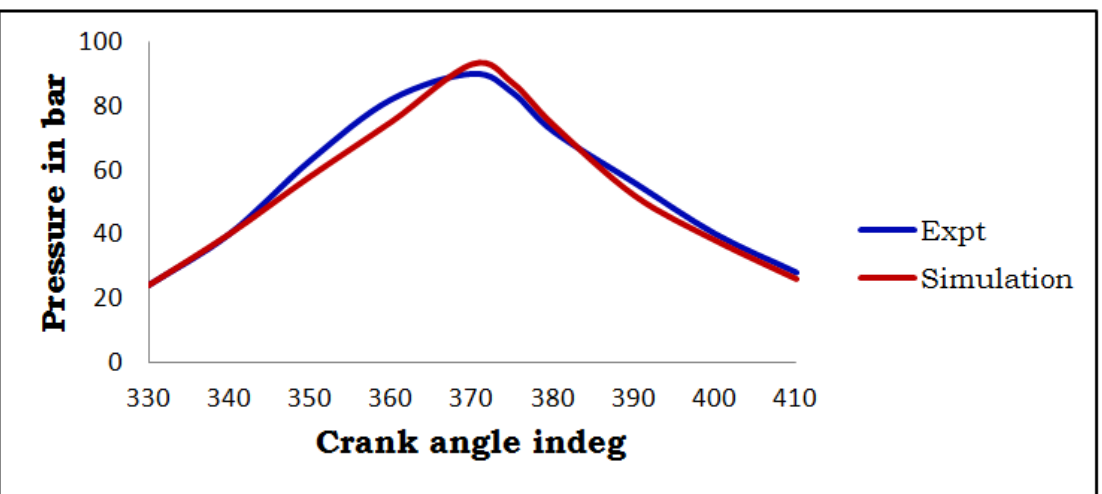

Figure 3 P- $\theta$ Curve for Triple injection

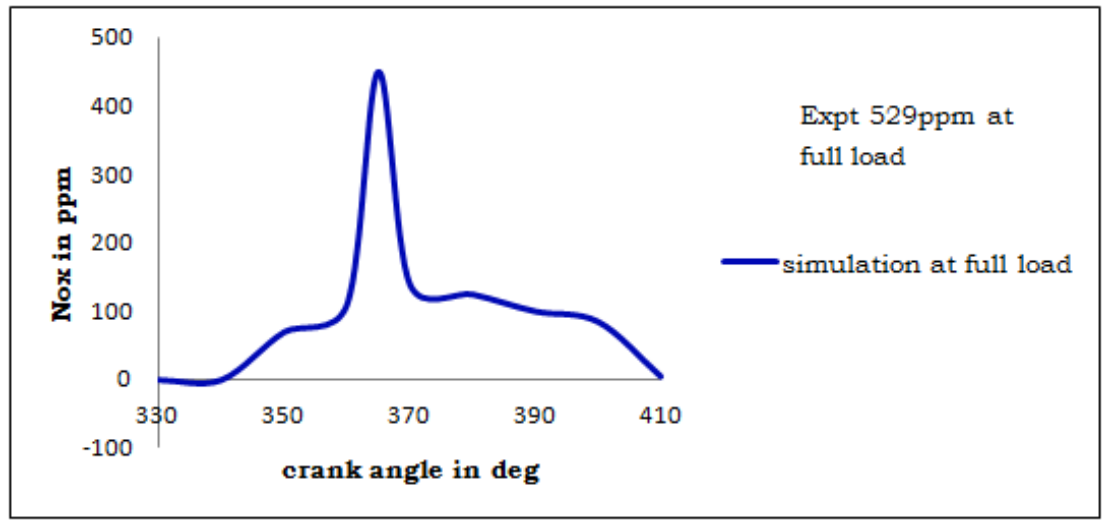

Figure $4 \mathrm{NO}_{\mathrm{X}}$ Curve for Single Injection 


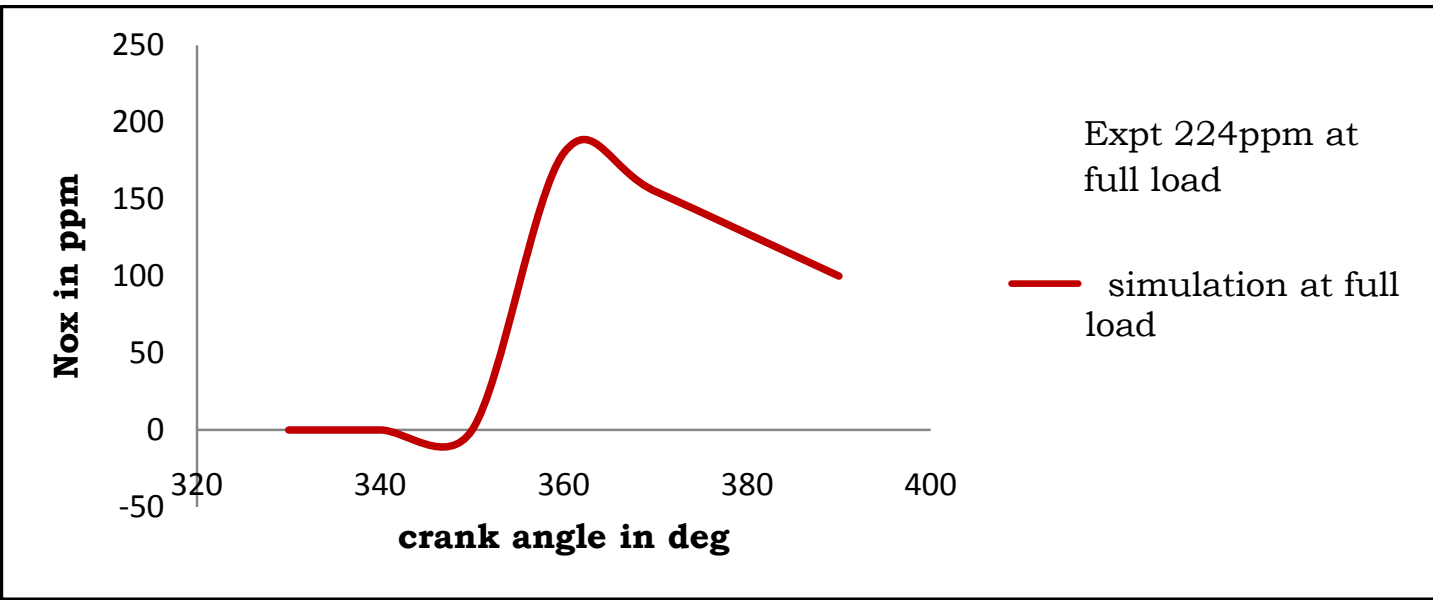

Figure $5 \mathrm{NO}_{\mathrm{X}}$ Curve for triple Injection

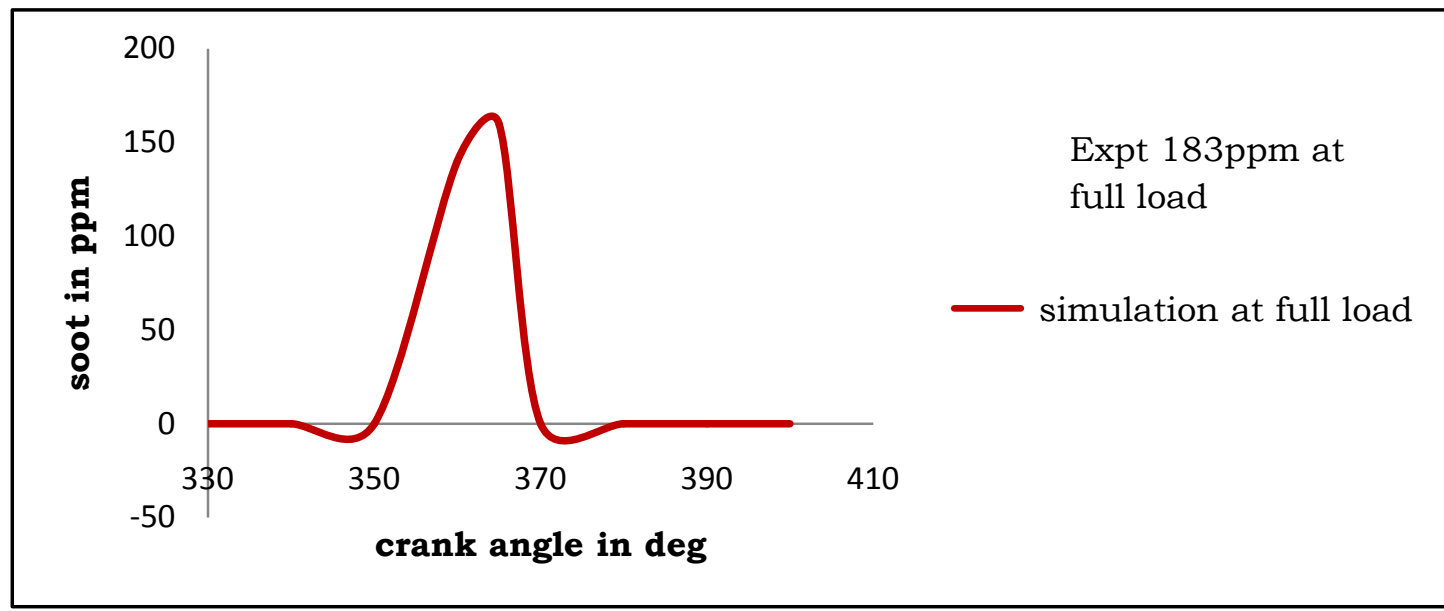

Figure 6 Soot curve for single Injection

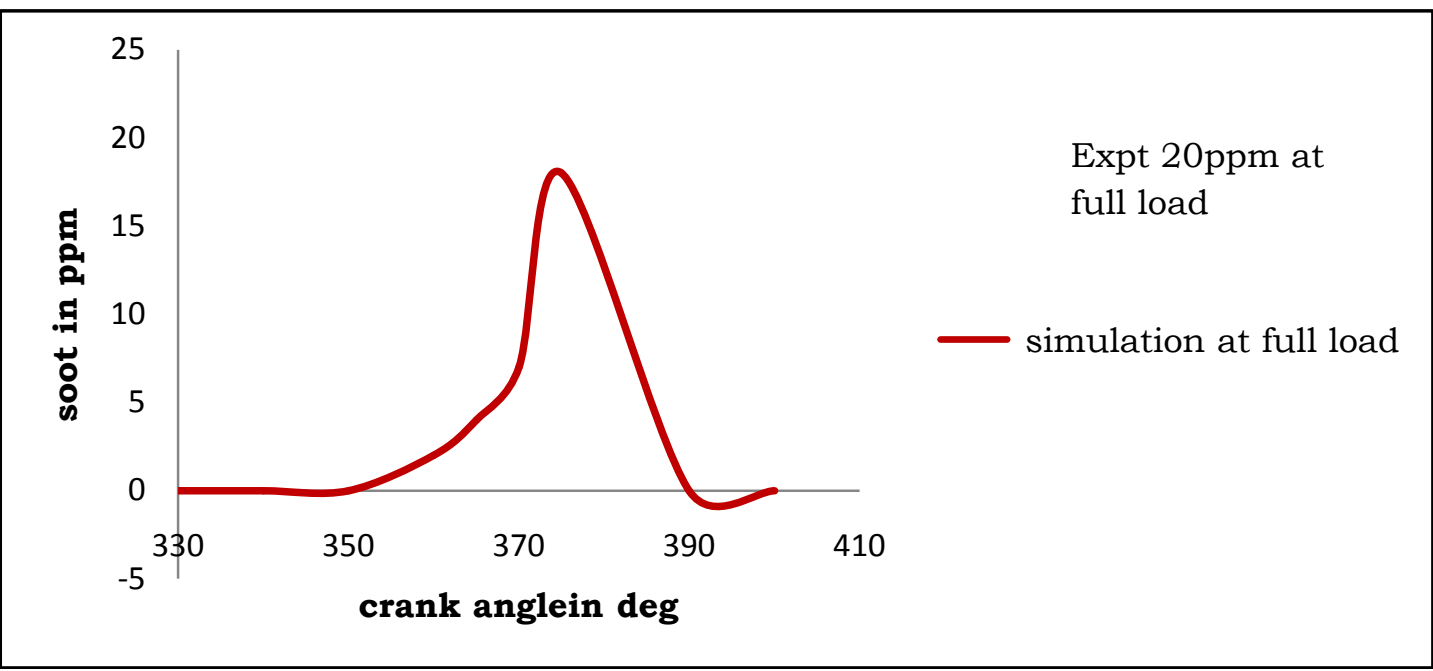

Figure 7 Soot curve for triple Injection

VII. Results And Discussions

Figs 2and .3 shows comparison of P- $\theta$ curves obtained by simulation to the existing experimental results for single and triple injections. For triple injection it was $20^{\circ}$. For single and double injection peak cycle Pressure has been increased nearly by $8.4 \%$ and for triple injection it was nearly $3.22 \%$. As number of pulses increases, peak pressure is closely following the experimental value. $\mathrm{NO}_{\mathrm{x}}$ curves are shown in Figs. 4and 5 International Conference on Recent Innovations in Civil \& Mechanical Engineering $\quad$ 47| Page [i-CAM2K16] DOI: 10.9790/1684-16053024249 
obtained by simulation and compared with the existing experimental results for single, double, and triple injections at full load [11]. For single and double injections $\mathrm{NO}_{\mathrm{X}}$ are reduced by nearly $15.01 \%$ and $27.7 \%$, where as for triple injection nearly $19.64 \%$ has been reduced. Figs 6 and 7 show comparison of soot curves obtained by simulation to the existing experimental results for single and triple injections. For single injection soot has been decreased $12.32 \%$ and triple injections there was a reduction by nearly $11.33 \%$ respectively.

\section{Contours}

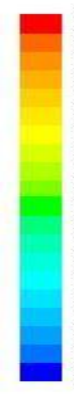

$3.87 \theta-102$

$3.87 e+02$

$3.87 e-02$
$3.87 e-02$

$3.87 e-05$
$3.87 e-02$

$3.87 e-02$
$3.87 e-02$

$3.87 e-02$

$3.86 e+02$

$3.86 e-02$

$3.86 e-02$

$3.86 e-02$

$3.86 e-02$

$3.86 e-02$

$3.86 e-02$
$3.86 e-02$

$3.86 e-02 x z$
$3.86 e-102$

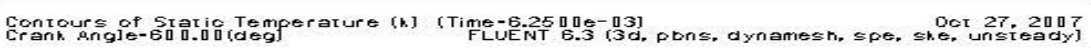
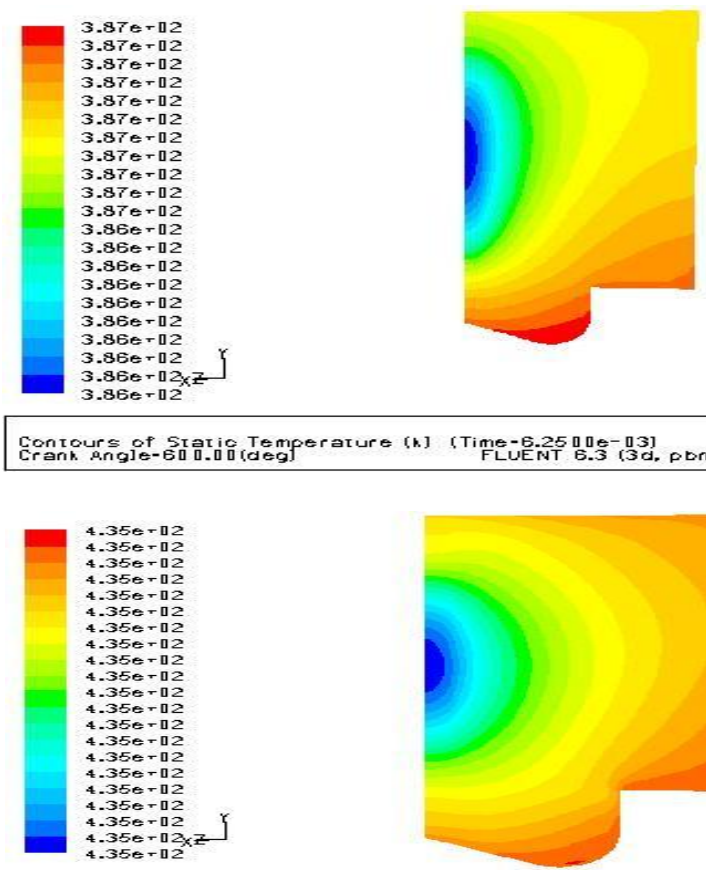

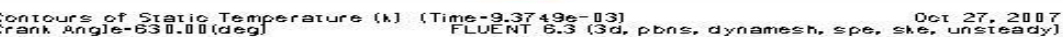

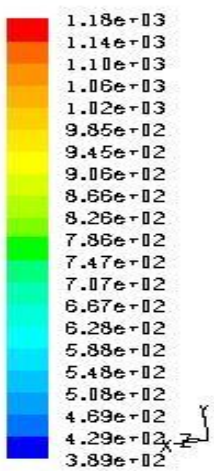

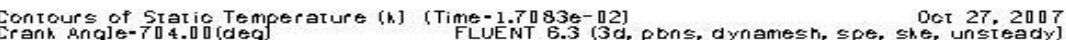

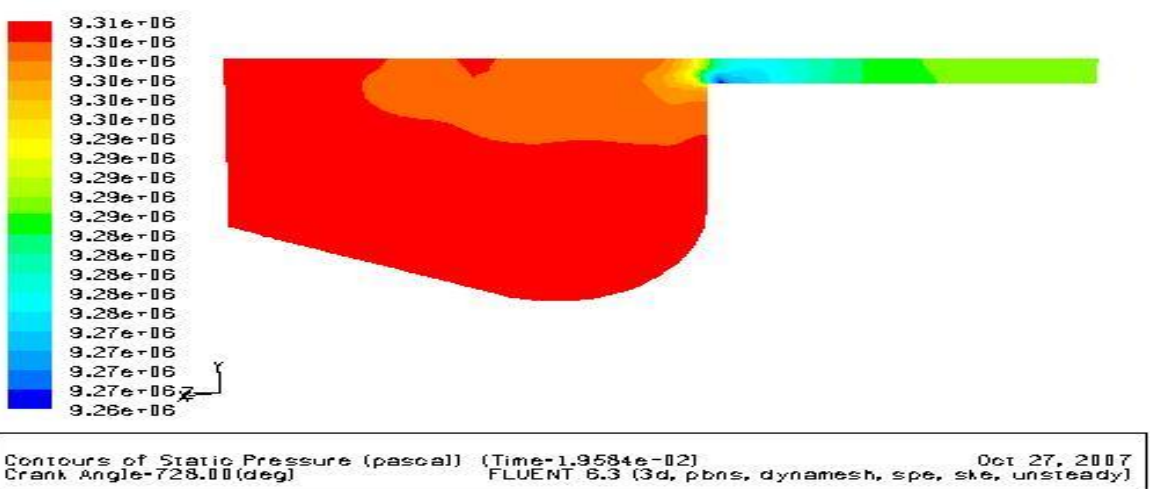



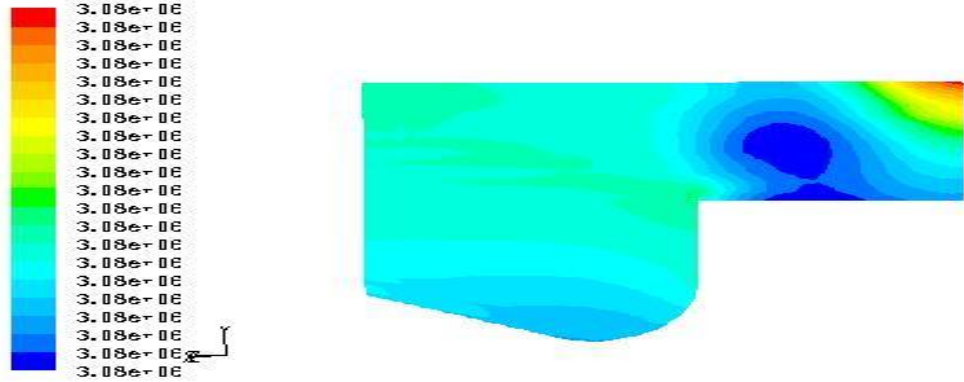

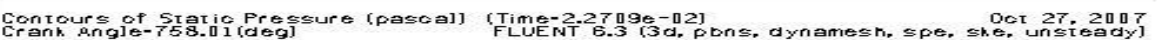

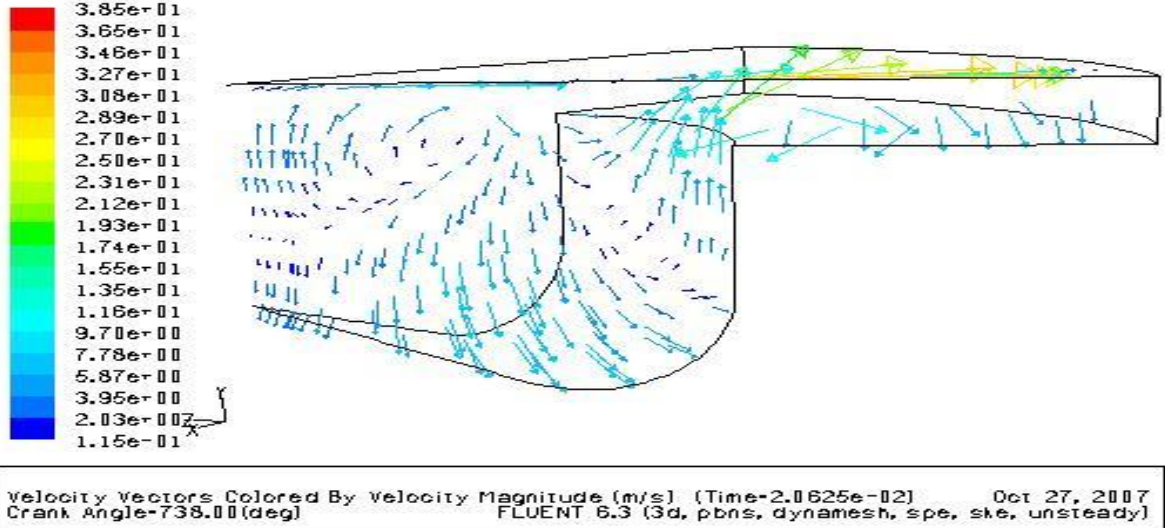

References

[1]. Fuchs, T.R. and Rutland, C.J., "Intake Flow Effects on Combustion and Emissions in a Diesel Engine", SAE Paper 980508, 1998.

[2]. Jafer, D., "Pilot Injection", Engineering. October 15, 1937.

[3]. Shundoh, S., Komori, M., Tsujimura, K., and Kobayashi, S., "NO $\mathrm{X}$ Reduction from Diesel Combustion Using Pilot Injection with High-Pressure Fuel Injection", SAE Paper 920461, 1992:25-36

[4]. Yamaki, Y. et.al. "Application of Common Rail Fuel Injection System to a Heavy Duty Diesel Engine", SAE Paper 94229, 1994:85-96

[5]. Miyami, T., Takeuchi, K., and Shimazaki, N., "Reduction of Diesel Engine $\mathrm{NO}_{\mathrm{X}}$ Using Pilot Injection". SAE Paper 950611, 1995:89-96

[6]. Zhang, Long, “A Study of Pilot Injection in a DI Diesel Engine”, SAE Paper 1999-01-3493, 1999:1-8

[7]. Nehmer, D.A. and Reitz, R.D., "Measurement of the Effect of Injection Rate and Split Injections on Diesel Engine Soot and $\mathrm{NO}_{\mathrm{X}}$ Emissions", SAE Paper940668, 1994:55-66

[8]. Tow, T.C., Pierpont, A., and Reitz, R.D., "Reducing Particulates and $\mathrm{NO}_{\mathrm{X}}$ Emissions by Using Multiple Injections in a Heavy Duty D.I. Diesel Engine", SAE Paper 940897, 1994:1-14

[9]. Han, Z., Ulugogan, A., Hampson, G.J., and R.D.Reitz, "Mechanism of Soot and $\mathrm{NO}_{\mathrm{X}}$ Emission Reduction Using Multiple -Injection in a Diesel Engine", SAE Paper 960633, 1996:87-102

[10]. Durnholz, M., Endres, H., and Frisse, P., "Pre injection A Measure to Optimize the Emission Behavior of DK-Diesel Engine “, SAE Paper 940674, 1994:123-129

[11]. D.A. Pierpont, D.T. Montgomery, and Reitz, "Reducing Particulate and $\mathrm{NO}_{\mathrm{X}}$ Using Multiple Injections and EGR in a D.I. Diesel" SAE 950217 1995:1-13

[12]. D. T. Montgomery and R. D. Reitz "Six-Mode Cycle Evaluation of the Effect of EGR and Multiple Injections on Particulate and $\mathrm{NO}_{\mathrm{X}}$ Emissions from a D.I. Diesel Engine" SAE 960316 1996:113-130

[13]. Manshik Kim and Rolf D. Reitz "Modeling Early Injection Processes in HSDI Diesel Engines" SAE 2006-01-0056 2006:3-14

[14]. Mark P. B. Heavy-Duty Diesel Engine" SAE 2006-01-0079 2006:1-30

[15]. Musculus "Multiple Simultaneous Optical Diagnostic Imaging of Early-Injection Low-Temperature Combustion in a

[16]. W. L. Hardy and R. D. Reitz "An Experimental Investigation of Partially Premixed Combustion Strategies Using Multiple Injections in a Heavy-Duty Diesel Engine” SAE 2006-01-0917 2006:1-20 